\title{
A Simulation and Fabrication Works on Optimization of High Pressure Aluminum Die Casting Part
}

\begin{abstract}
S.Ö. ERTÜRK ${ }^{a, b}$, L.C. KUMRUOĞLU ${ }^{a, b, *}$ AND A. ÖZEL ${ }^{a, b}$
${ }^{a}$ Metallurgical and Materials Engineering Department of University of Sakarya, Esentepe, 54187 Turkey

${ }^{b}$ Metallurgical and Materials Engineering Department of University of Cumhuriyet, Sivas, Turkey

High-pressure die casting offers reduced costs due to its small tolerances and smooth surface finish. Casting parts produced are consumed by the automotive industry in millions. In this study, the use of computer aided engineering applications on design of high-pressure die-casting was studied. The influence of casting process steps in die design was studied and analyzed. The casting simulation software was used to improve design and solve problems. By using the simulation software in analyses of die design, the final design was reached in a few hours and thus the design process of pre-production was shortened and mold production was carried out with no revision on die material. Radiographic test was applied on the casting parts and the result shows good correlation between simulations of solidification result data. Also the results proved that the application of squeeze pressure in the intensification phase of high-pressure die casting process could be examined in the casting simulation.
\end{abstract}

DOI: 10.12693/APhysPolA.125.449

PACS: $81.20 . \mathrm{Hy}, 81.05 . \mathrm{Bx}$

\section{Introduction}

The goal of any manufacturing industry is to minimize the processing steps to produce a more economical final product. This goal is accomplished by the so-called "net shape manufacturing". Die casting using a horizontal cold chamber machine is currently the most common process for manufacturing near net shape cast components of aluminum and magnesium alloys [1]. Also the pressure die casting has the greatest capability for reproducibility of dimensions [2]. Approximately half of all castings worldwide made of aluminum alloys manufactured in this way are used for a wide range of automotive parts and the other consumer goods [3]. In horizontal cold chamber process, the liquid metal was pushed by a plunger through a horizontal shot sleeve and injected into a mold [1]. The injection of liquid metal is generally at high velocities promoting turbulent flow that can result in air entrapment with the initial air in the mold [4]. The presence of gas porosity in castings is harmful as the mechanical properties and pressure tightness are adversely affected [5].

To remove the initial air in the mold, ventilation channels and to remove the air entrapped liquid metal, overflows are used in high pressure castings' die design. The injection of liquid metal is carried out in two separate steps that are slow and fast shot phases. In the slow shot phase, the plunger forces the liquid metal to rise and fill the empty portion of the shot sleeve. The fast shot phase is the injection of liquid metal to the mold cavity in milliseconds. So the computer simulation is very necessary for controlling the cavity fill and the determination of

*corresponding author; e-mail: Ikumru@cumhuriyet.edu.tr the ventilation channels and overflows right location in the mold. There are different theoretical and experimental studies about die design for high pressure die casting but none of them presents using computer simulation in step by step die design and the advantages via trial-error method [6-8].

\section{Design and production}

Getting started with the design of the mold for high pressure die casting die, a vital entry point is the location of the ingates and runners. Turbulence caused gas porosity problems of casting occur because of the wrong ingate location. When the solidification of our casting part was examined by computer simulation, the last solidified regions have been seen in Fig. 1. The other vital point
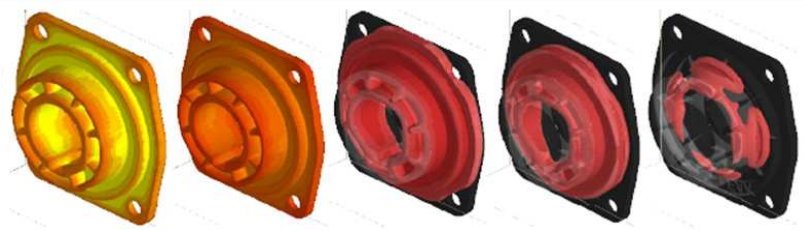

Fig. 1. Solidification steps of casting part.

for the determination of this parting line of mold is the ability of casting part's remove from the mold after the solidification. The remove of the part is firstly with the moving half of the mold from a fixed mold half, and then with the help of the ejector pins removing from the moving half of the mold. The mold of our sample work piece contains cores for providing the internal cavities. Because of the volumetric shrinkage during solidification of casting part these core elements of the mold are squeezed by the casting part. For removing of the casting from the fixed mold half, the surface area of the part-core contact 
on the moving mold half must be larger than the surface area of part-core contact on the fixed mold half. Thus the friction force against the remove of the part from the fixed mold half can be beaten by help of the friction force on the moving half of the mold. At this step the CAD software's measurement functions should be performed. According to this case and the measurements mold parting line were founded as shown in Fig. 2. The surfaces that have to be applied draft angles due to mold halves are shown in Fig. 2b.
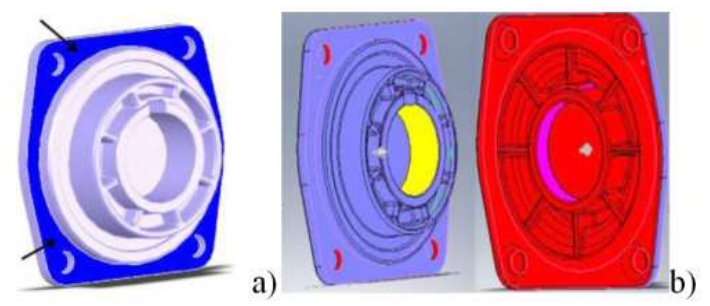

Fig. 2. (a) Mold parting line, (b) draft analyses of casting part.
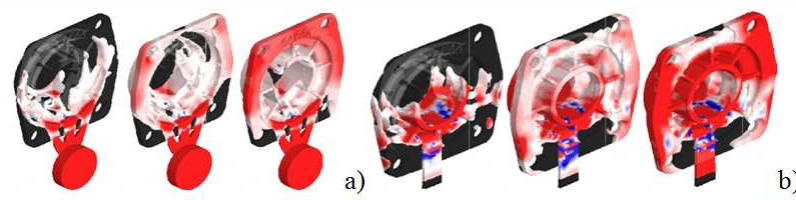

Fig. 3. (a) Mold filling of model with three ingate, (b) mold filling of model with single and thin ingate.
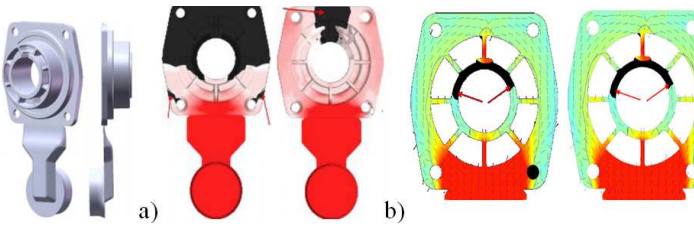

Fig. 4. (a) The solid model of casting part with emitter type ingate, (b) possible air entrapments in part, (c) possible air entrapments from section.

For the production of near net shape casting part, the contraction allowance, $0.7 \%$ for the selected alloy and H13 mold material is added. The determination of ingate type and position is also important for the filling of mold cavity. In pressure die casting, the incorrect filling pattern causes defects in casting parts and damages in mold material. Various fill patterns formed due to the type and the position of ingate, have been investigated by casting simulation. By using the simulation software, the designer can get experience and would be freed from the disadvantages of cost and time-consuming. In Fig. 3a and $b$ the fill patterns with two different ingates were examined. Accounted for due to the fill patterns, there are trapped air regions where the ventilation is not possible.
To avoid this kind of defects, single and emitter type ingate has been added to the model.

Again, while selecting the position of ingate, the direction of solidification in casting part was investigated. Accordingly, one of the appropriate two-piece flat surface was chosen because the shaft bearing region caused a thin section and early solidification occurs on the feeding path.

This is known as the ingate blockage and has been detected by researchers in different studies by using pressure sensors [5]. The fill pattern with the single and emitter type ingate is shown in Fig. 4. After determining the type and location of the ingate, the fill time for the mold cavity and cross-sectional area has to be calculated. This cross-sectional area determines the flow velocity of the liquid metal at the ingate and inside the mold cavity. The high speeds of liquid metal causes erosion in the mold and to prevent this defect there are velocity limits variances due to alloy given in Table.

TABLE

Fill times due to section thickness of casting part.

\begin{tabular}{c|c}
\hline \hline Section thickness $[\mathrm{mm}]$ & Fill time $[\mathrm{ms}]$ \\
\hline 1.5 & $10-30$ \\
1.8 & $20-40$ \\
2 & $20-60$ \\
2.3 & $30-70$ \\
2.5 & $40-90$ \\
3 & $50-100$ \\
3.8 & $50-120$ \\
5 & $60-200$ \\
6.4 & $80-300$
\end{tabular}

According to literature the fill time was found from Table due to mean thickness of part. By dividing the volume of mold cavity to form the casting part to the required fill time, the necessary flow rate can be found. After giving relationship between the required flow velocity of melt and cross-section area with the law of continuity in the calculation, $Q=V \times A$, where $Q$ is flow rate, $V$ is the speed of melt, and $A$ is the section area. The calculated flow rate for the part is $4660 \mathrm{~cm}^{3} / \mathrm{s} .30 \mathrm{~m} / \mathrm{s}$ ingate velocity was aimed with thickness of $2 \mathrm{~mm}$ and $77.6 \mathrm{~mm}$ length ingate dimensions. In this model for determining the position of ventilation channels and overflows, the filling simulation has been carried out with $0.5 \mathrm{~m} / \mathrm{s}$ first phase and $2.5 \mathrm{~m} / \mathrm{s}$ second phase plunger speed. According to the simulation of mold filling, the potential air entrapment regions were shown in Fig. 4a and b. Due to these results, the ventilation channels and overflows on the end of these channels were added to the design as shown in Fig. 5.

When the filling simulation of the revised design was analyzed, colliding streams were seen at the top of the core (Fig. 5a). In order to avoid both the collision at the top of the core and the possible turbulences on the top lateral mold walls, overflows have been added to the mold 


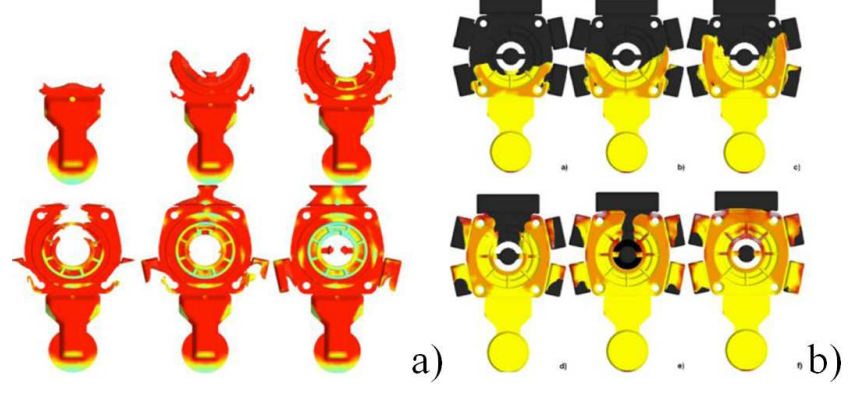

Fig. 5. (a) Mold filling with three overflows attached model, (b) mold filling of part with five overflows.

cavity. Also the change in the fill pattern was aimed by adding these overflows (Fig. 5b). When the filling simulation of final design was examined, we saw that the actual collision at the top of core was unavoidable. But remove of turbulence melt (due to the collision) to the top overflow pocket was determined according to the filling simulation results. Finally, in the results of complete simulation (the compression force was defined) of the final mold design there was no shrinkage defect seen due to the compression of liquid metal.

\section{Radiographic testing}

After cutting runner and overflows from the part, radiographic examination was carried out. The radiographic examination of applied by Baltospot GFD Industrial X-ray device screen with Kodak MX123 was according to the EN 12681 and EN 444 testing and standards. The result of the radiographic inspection was shown in Fig. 6.
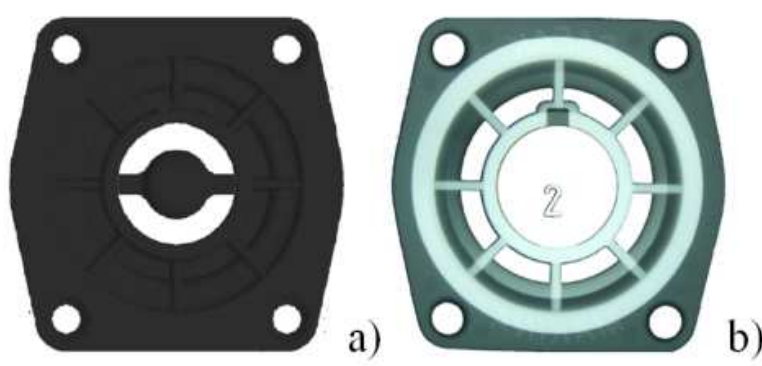

Fig. 6. (a) The shrinkage view from simulation result, (b) the radiographic result of casting part.

\section{Results and comments}

One of the main goals of casting simulation is to avoid defects that may occur during mold filling such as turbulence and air entrapments. The other is to prevent economical and time losses caused by traditional trial and error method. In this study, the final design was reached in a few hours by using the computer simulation from the first steps of design. Thus, the design process of pre-production was shortened and mold production was carried out with no revision on die material. Radiographic examination of the produced parts, there was no defect seen in visible dimensions inside the part that could cause a denial of production and prove the accuracy of the design and calculated production parameters. The overlap of radiographic test results with the solidification simulation results showed that computer simulation showing the effect of solidification compression force has been an indicator of the successfulness of casting.

\section{References}

[1] A. Jalili Nikroo, M. Akhlaghi, M. Ahmadi Najafabadi, Int. J. Adv. Manuf. Technol. 41, 31 (2009).

[2] J. Campbell, Mater. Des. 21, 373 (2000).

[3] P.K.D.V. Yarlagadda, E. Cheng Wei Chiang, J. Mater. Proc. Technol. 89-90, 583 (1999).

[4] X. Dai, X. Yang, J. Campbell, J. Wood, Mater. Sci. Eng. A 354, 315 (2003).

[5] X.P. Niu, B.H. Hu, I. Piwill, H. Li, J. Mater. Proc. Technol. 105, 119 (2000).

[6] B.H. Hu, K.K. Tong, X.P. Niu, I. Pinwill, J. Mater. Proc. Technol. 105, 128 (2000).

[7] F. Shehata, M. Abd-Elhamid, Mater. Des. 24, 577 (2003).

[8] W.S. Zhang, S.M. Xiong, B.C. Liu, J. Mater. Proc. Technol. 63, 707 (1997). 